\title{
IMPROVING NEW ZEALAND HEALTH OUTCOMES WITH ARTIFICIAL INTELLIGENCE
}

\section{Tavish Sehgal and Marianne Cherrington}

\section{INTRODUCTION}

Aotearoa New Zealand has a quality, government funded health care system with public health services plus primary (first point-of-contact) and secondary (specialist) health care. Private healthcare providers are also utilised for overall assured care. Around the motu, islands of healthcare inequity exist.

Significant inequality is evident in various demographics within New Zealand (Ministry of Health, 2002). Health inequalities are a major health issue that affect society as a whole in complex and compounding ways. For example, health is correlated with poverty, and the latter is linked to education, profession, earnings and deprivation (Moore et al., 2018; Khan, 2012); cultural background, social groups, and nationality are additional factors that influence health (Arcaya et al., 2015). Solutions to health inequity can be complex and often have unintended consequences that may be hard to predict.

Artificial intelligence (Al) can be thought of as "a system's ability to interpret external data correctly, to learn from such data, and to use those learnings to achieve specific goals and tasks through flexible adaptation" (Kaplan, \& Haenlein, 2019, p. 15). Machine learning (ML) is a subfield of Al that automates processes to achieve objectives, improve predictions or inform decisions (Cherrington et al., 2019c). Deep Learning (DL) uses artificial neural networks to activate $\mathrm{Al}$ applications. These technologies can be relatively easy and cost effective to apply. For example, Al supported swift, effective COVID-19 response:

- by detecting and diagnosing SARS-CoV-2 virus, also known as COVID-19 (Cherrington et al., 202lb),

- via intelligent, analytic platforms to monitor or predict the spread of Covid-19 (Kvalsvig et al., 2020),

- by using contact tracing technologies of individuals (Lalmuanawma et al., 2020),

- through the prediction of the spread of infection and possible mortality rates (Vaishya et al., 2020),

- with the creation of efficacious drugs and vaccines (Kannan et al., 2020).

The beauty of digitised data systems is that machine learning trains itself better with more and more data; $\mathrm{Al}$ learns continually from every interaction and application, without respite (Maddox, 2019). Healthcare solutions using $\mathrm{Al}$ and machine learning are already in use globally and feature in parts of the healthcare system in New Zealand. This report does not consider ethical issues relating to privacy, consent, autonomy and so on, as extensive scholarship and debate is on-going. Rather, the next section will summarise transformative Al health applications with implications for health equity. Following this section, superior Al healthcare applications in New Zealand will be given. The conclusion will highlight a visionary pathway utilising Al that can lead to more equitable health coverage and better health outcomes. 


\section{ARTIFICIAL INTELLIGENCE APPLICATIONS IN HEALTHCARE}

Artificial Intelligence and associated ML technologies are becoming ubiquitous in society and in business. In particular, Al is used in healthcare, especially with applications that are too expensive or complex to be solved by human beings (Davenport \& Kalakota, 2019). Medical practice is being revolutionised with artificial intelligence. Al applications are emerging into realms that were previously recognised to be only the domain of human expertise, now accessible with advances in digitised data collecting, machine learning, and computing infrastructure (Yu et al., 2018). According to Jiang et al. (2017), the objective of artificial intelligence (Al) is to imitate human intelligence, and with $\mathrm{ML}, \mathrm{Al}$ can augment human decision-making. A radical shift in healthcare is on the horizon, due to the increasing availability of digitised healthcare data via a variety of structured or unstructured sources that are linked in ways that were previously not viable (Cherrington et al., 2019a, 2019b). The rapid advancement of ML techniques makes Al applications formidable and powerful tools.

Structured $M L$ data, such as support vector machines or deep learning (DL) using artificial neural networks (ANNs), alongside natural language processing are all popular Al techniques (Cherrington et al., 2020, 202la; 202Ic) and are particularly utilised in health applications (Figure I):

\begin{tabular}{|c|c|c|}
\hline & Artificial Intelligence Applications & Machine Learning Applications \\
\hline Neurology & $\begin{array}{l}\text { clinical decision support } \\
\text { (Pedersen et al., 2020) } \\
\text { prognosis of neurological disorders } \\
\text { (Patel, 202I) }\end{array}$ & $\begin{array}{l}\text { precision psychiatry/ specificity } \\
\text { (Bzdok et al., 20I8) } \\
\text { neuroimaging biomarkers } \\
\text { (Bernstein et al., 2018) }\end{array}$ \\
\hline Oncology & $\begin{array}{l}\text { precision oncology diagnostic tools } \\
\text { (Bera et al., 2019) } \\
\text { radiomics/ biomarker models } \\
\text { (Forghani et al., 2019) }\end{array}$ & $\begin{array}{l}\text { cancer genomics/ precision medicine } \\
\text { (Xu et al., 2019) } \\
\text { inter-drug response/ prediction (Ali \& } \\
\text { Aittokallio, 2020) }\end{array}$ \\
\hline Cardiology & $\begin{array}{l}\text { cardiac imaging/ preventatives } \\
\text { (Dilsizian et al., 2018) } \\
\text { interventions/ procedure support } \\
\text { (Sardar et al., 2019) }\end{array}$ & $\begin{array}{l}\text { foetal imaging/ diagnosis } \\
\text { (Garcia-Canadilla et al., 2020) } \\
\text { digital-led disease prevention } \\
\text { (Vervoort et al., 2020) }\end{array}$ \\
\hline Genetics & $\begin{array}{l}\text { pharmaceutical drug repurposing } \\
\text { (Zhou et al., 2020) } \\
\text { immunoprofiling/ image analysis } \\
\text { (Koelzer et al., 2019) }\end{array}$ & $\begin{array}{l}\text { disease/ gene functional analysis } \\
\text { (Asif et al., 20I8) } \\
\text { genotype disease prediction } \\
\text { (Katsaouni et al., 202I) }\end{array}$ \\
\hline
\end{tabular}

Figure I. Selected Artificial Intelligence and Machine Learning uses in Neurology, oncology and cardiology

Fields such as neurology, oncology, cardiology and genetics are four specific branches of medicine that use artificial intelligence (Yu et al., 2018) (Figure I); health applications can range from context specific (Madanian et al., 2018,2019 ) to general well-being solutions (Airehrour et al., 2020). Al is particularly useful in certain aspects of healthcare, yet less appropriate in others. While machine learning can always support data-driven discovery and decision-making, advances in imaging and Al automation are making these technologies more useful many more branches of medicine, and advances are intensifying.

The volume and variety of data due to digitisation has led to innovative solutions using big data ML methodologies in healthcare. Powerful Al algorithms can reveal clinically important information hidden in vast amounts of data, which can aid clinical decision making, when guided by relevant clinical queries (Jiang et al., 2017). Research has 
proven that Al can perform as well as or better than humans at crucial healthcare activities like disease diagnosis (Davenport \& Kalakota, 2019). For example, algorithms are already surpassing radiologists in terms of detecting dangerous tumours as well as advising researchers on how to build cohorts for expensive clinical trials. Concerns about Al taking human jobs in the healthcare sector are likely unfounded; it will be years before Al can begin to replace humans in extensive healthcare process domains for a variety of reasons (Meskó et al., 2018). There is a dire need for healthcare workers, exacerbated by the COVID-19 pandemic. Al is best used as a support and safeguard.

Clinicians, managers, and decision-makers can use healthcare data for education or to target a wise use of healthcare resources. Machine learning is used to produce data-driven prediction but also to drive a variety of Al technological advancements that are creating ground-breaking treatments and supporting patient rehabilitation. The future of $\mathrm{Al}$ in medicine will ameliorate many healthcare challenges; robotic process automation, computer vision, natural language processing, reinforcement learning, and generalised deep learning are in use already; enhanced equity can be attained now, via Al applications.

\section{STATE-OF-THE-ART ROBOTICS IN HEALTHCARE}

Just as the world is grappling with how to live with a pandemic and the incalculable toll of COVID-19, strategies and forward progress is being made. As vaccination rates progress, former health dilemmas that were pushed aside are being debated again. Health equity and 'haves-and-have-nots' are key issues.

Fortunately, we are at a point where a confluence of technological solutions is combining to make artificial intelligence and machine learning pertinent for the moment. Healthcare challenges such as those linked to resourcing, can be assuaged with novel technological applications. Currently, the opportunity to make the most of data to foster and leverage equity in healthcare has never been greater.

For example, machine learning can be used for prediction, vital in healthcare. Forecasting treatment efficacy, pharmaceutical regimes or likely patient behaviours can be conflated and nuanced with trained data. Data used in conjunction with deep learning (inspired by human thinking) or robotics can transform access to healthcare for more people to close inequities and inaccessibility that leads to poor health.

Digital disruption in medical fields, enabled by big data accessibility is already supporting personalised healthcare (Puaschunder et al., 2020). Benefits such as greater efficiency, quality and accuracy can be realised for more people with less financial outlay. Rather that de-valuing the need for specialised health workers and medical experts, artificial intelligence can become their ally in a quest for health equity. In particular, great strides have been made in functionality of robotics in the healthcare sector, including:

- Surgical robots used in therapeutic areas for minimally invasive robotic surgery

- Care robots to assist with routine, emotional or palliative nursing rounds

- Exoskeletons created to support patient recovery/ rehabilitate regimes, as well for prosthetics

- Hospital robots navigate wards with medications or specimens using, sensors and maps.

Precision operations and accuracy measures with robots have been explicitly adapted for computer-integrated surgery (CIS). In CIS, a tracked device is typically steered (directed) to various positions and orientations along a well-defined set of landmarks (fiducials). An independent localiser, usually an optical tracking system, is used to record these positions (Haidegger et al., 2019). Robotic surgery necessitates a high degree of accuracy and CIS provides a number of ways to improve and complement human dexterity.

Robot-assisted initiatives have been around since the mid-1980s, but are now extensively used in surgical fields due to their intensifying adaptability and operating theatre consistency. In neurosurgical fields, they improve quality of 
various operative practises, especially those demanding a greater precision or safety profile (Kapoor et al., 2019). Robot-assisted surgery has sophisticated surgical incision which results in a lowered pain in recover and less time in hospital; fewer drugs and days in hospital care is cost-effective.

Physical robots are becoming a part of everyday life in key industries; what was once considered science fiction has now become reality. The advancements in robotics in everyday life benefit everyone in the developed world today, with flow-on effects and ubiquitous technologies (Hockstein et al., 2007). Physical robots can execute predefined activities in situ, such as lifting, repositioning, and transporting supplies in hospitals. Robots have recently become more collaborative with people and are easier to teach by guiding them through a desired job. They are also becoming smarter as more Al capabilities are integrated into their 'brains', or operating systems. The same advancements in intelligence that we have seen in other areas of Al are likely to be applied into physical robots over time (Runciman, 2019).

Surgical robots, which were first approved in the United States in 2000, support surgeons, allowing them to see better, make more precise and least invasive incisions, stitch wounds, and so on. However, human surgeons continue to make important judgments. Gynaecologic surgery, prostate surgery, and head and neck surgery are all common surgical procedures that use robotic surgery (Davenport \& Glaser, 2002).

Surgery has proven to be a comprehensive discipline capable of treating a wide range of diseases and disorders as technological improvements continue to develop throughout the decades. In response, as computer technology and software improve, similar technologies are being implemented in the operating room as well. Finely operated robotic surgery platforms have found a rich young market in the medical technology sector, thanks to the late popularisation of minimally invasive procedures and surgeries. In fact Minimally Invasive Surgery (MIS) robotics operations account for the bulk of the surgical robotics market.

MIS techniques and MIS robotics help the general population as well; laparoscopic surgery, is used on patients diagnosed with many different conditions and has replaced many complex surgeries that have long recovery times. MIS robotics is already creating more equitable and affordable health outcomes, especially in cities with large populations, such as in Auckland where the da Vinci surgical system has been used. The da Vinci robotic system from Intuitive Surgical Inc. is arguably the most successful surgical robot in use and is currently the only complete teleoperation surgical robot accessible. Developed with a $\$ 500$ million investment, it can carry out sophisticated surgical procedures using laparoscopic technology while being guided remotely by a competent physician (Haidegger et al., 2019).

One aim of robotic surgery is to be able to do a surgical procedure from a distance without having to touch the patient. The Arthrobot, followed voice directions to help in patient positioning during an orthopaedic surgery operation and the Unimation Puma 200, which was used to orient a needle for brain biopsy were the first surgical robots (Smith et al., 2016). ZEUS, a comprehensive robotic surgical system with tremor reduction and motion scaling, was the first robotic surgical system (Ranev \& Teixeira, 2020) approved by the U.S.A. Food and Drug Administration. The first long-distance, tele-surgical procedure, a laparoscopic cholecystectomy on a French patient in Strasbourg while the surgeon was in New York, was performed with the help of ZEUS (Marescaux et al., 2006). Another innovation was Intuitive Surgery's Da Vinci robotic system, which is utilised in a range of surgical specialties for a variety of operations to conduct technically demanding treatments (Troccaz et al., 2019). Several other robotic devices for various surgical procedures across several disciplines have since been created and are now more commercially accessible for general use.

Medical science is finding ways to utilise robots to liberate a stressed and often over-worked healthcare labour force. Robots are now interacting with patient, staff and assisting administrators. Routine and complex surgical techniques are now more commonly performed by skilled robotics. Increasingly healthcare management is turning to $\mathrm{ML}$ and $\mathrm{Al}$ to assist with countless aspects of hospital and health management, as routing patient care and complex processes can be handled or at least supported by these innovative technologies (Alotaibi \& Yamin, 2019). 
Can the benefits of $\mathrm{Al}$ in healthcare become a solution for beleaguered hospitals and our workforce? Robotics is a particularly visible and innovative application that is being used in healthcare (Bogue, 20II). Research and innovation can add value in New Zealand as well, but it is vital to assess what is feasible and what is not, with possible impacts and ways in which New Zealand might proceed.

\section{THE CURRENT STATE OF HEALTHCARE}

Charitable organisations that 'fill in the gaps' can use ML and Al to do more with less. Where aid or education is needed to improve health or for public health initiatives, virtual medical centres can use digital instrument data, with cloud diagnostics for holistic treatment plans can be delivered (Field \& Butler, 20l8). Even as wearable activity trackers have become more affordable, they are being used routinely to aid health programmes that foster health, wellness and wellbeing (Madanian et al., 20l8).

At the other end of the scale, innovations in high dimensional DNA sequencing and micro-array analysis impact significantly on the personalised healthcare market (Peng et al., 2018); novel applications include:

- computational biology where bioinformatic genetic data have breakthroughs revolutionise diagnosis and treatment of disease

- diagnostics and health research using Al visualisation for applications such as tomography, use digitisation to visualise insights or support diagnoses

- data mining and machine learning fast-track pharmaceutical innovations and design, with high throughput methods automating processes by specifying candidate features

- medical imaging processes which can be automated with Al and can detect malignant cancers with accuracy, for example

- deep learning that drives Al, which can also be used to search for solutions that may not be discernible by experts, due to the sheer volume of data accessed.

New genetic discoveries are resulting from Al, which in turn can create new and unique insights for human health. Personalised prescriptions are becoming available with pharmacogenomics that merge genetic testing and biomarker data from electronic health records. The discoveries that Al advance will not only help those wealthy enough to afford novel treatments, but as these innovations become more ubiquitous and affordable, personalised prescription will become a more efficacious method of treatment (Hall, 2020).

The COVID-19 epidemic has altered our planet, impacting people from all walks of life. Frontline workers, especially those in direct contact with patients, are put in grave danger. We have seen the use of robots as a shielding layer, physically isolating healthcare professionals from patients, as a significant technique for combating pathogen contamination fears and maintaining surgical volumes (Zemmar et al., 2020).

COVID-19 has severely limited health services, with cancellation of elective surgeries to reduce the spread of disease and protect healthcare personnel and patients. This has resulted in a significant burden for patients and a significant financial loss for hospitals. Yet even in New Zealand, where COVID-19 has largely been kept at bay, the "health system is failing to cope" and services are under stress due to "demand, the complexity of procedures, industrial action and workforce shortages" (Jones, p. Al., 202I).

Nurses are set to strike in New Zealand again. Emergency rooms have been overflowing across the country for months, even without any community COVID-19 transmission. Reports are of junior nurses, left to triage with more than 40 patients, some of whom have 24 hour plus waiting times to access ward admission. To manage patient demand and keep staff safe, new measures include monitoring of clinical staffing during peak periods, access to security backup, plus a review of visitor policy (Campbell, 202I). It is perplexing that a supply of COVID-19 syringes must suddenly be urgently ordered now, even after a vaccination slowdown as New Zealand had to wait for a new supply of vaccine (Coughan, 2021). 
These issues and stop-gaps will not resolve healthcare inequity or improve access to expert care.

Machine Learning can better predict ebbs and flows in healthcare services and Al robotics can support doctors and nurses while augmenting safety practices. Exhaustion leads to mistakes. Al platforms can streamline or scale hospital operational processes, optimise surgeries and predict downtimes or specialist availability (Graue, 20I3). Such scheduling support can save untold hours, resources and expense for more efficient medical and hospital care when and where it is needed most, such as triage (Levin et al., 2018).

\section{STATE-OF-THE-ART HEALTHCARE IN AOTEAROA}

As nurses are in short supply and under-paid while hospitals are overcrowded in New Zealand, we might be thankful that the ravages of COVID-19 have largely been kept at bay in this country. We might wonder if state-ofthe-art, equitable healthcare is a possibility; it surely must be a case of re-resourcing.

Machine learning, when used well, can support wise decisions based on real data, including behavioural information. In a predictive sense, this can allow for wise deployment of skilled labour, funds and assets.

Digital people are a product of amazing Al research by Soul Machines, begun in New Zealand. The lifelike creations deliver amazing customer experience in sectors like entertainment, financial services, retail and education and are used in healthcare too (Soul Machines, 2020). As Digital Healthcare aides, they answer questions about health conditions, speak several languages and so office clerical tasks on a 24/7 basis.

Dr. Lance O'Sullivan says the "opportunity with Soul Machines digital health professionals is to be able to deliver more care to more patients for less cost." Combined with the digital teacher abilities, it is easy to imagine how routine hospital tasks could be performed by digital people to release expertise where it is most needed in medical settings.

For health initiatives like MAiHEALTH delivering health outcomes via virtual medical centres or iMoko, where digital instrument data is used virtually with cloud-storage, processes from diagnosis to multi-faceted treatment plans are fast and efficacious (eHealth News Features, 2019). iMoko offers personalised healthcare not for the rich and famous, but for underprivileged children, to ensure better health outcomes and more time in class rather than in doctor's rooms. Partnerships make schemes work, so iMoko also partnered with Otago Polytechnic for microcredentialing for the new digital health work-force behind the digital iMoko project.

Targeted campaigns can improve health outcomes and with continuous data from wearables, mHealth plans deliver cost-effective healthcare quickly, before health issues escalate into ICU crises. Even insurers are getting onboard with discounted rates and benefits for members who utilise wearables and share their data (AIA, Sovereign and You, 2019).

Another way to share data is through research. New Zealand is uniquely placed to develop Al technologies due to exceptional longitudinal research like "The Dunedin Study", with over twenty years of human health data (Belsky et al., 2020); new insights into genetic predisposition and hereditary conditions are being found.

Other firms in New Zealand are at the forefront of healthcare. Pinnacle Ventures pharmacogenomics programme is pioneering personalised prescriptions with biomarker information on electronic health records (Health Informatics New Zealand, 2019). Similarly, Precision Driven Health is focusing healthcare decisions in conjunction with genetic testing (Health Informatics New Zealand, 2019) and oDocs is auto-diagnosing with a world-first Al platform (Orion Health, 2019). Artificial Intelligence is already world-class in New Zealand and already being used to create more equitable and exquisite healthcare solutions for a range of New Zealanders. 


\section{CONCLUSIONS}

Attaining equity in healthcare matters more than ever. Across the world and our nation, gaps in health are great, persistent and increasing - many of them caused by barriers set up at all levels of our society. After all, it is hard to be healthy without access to good jobs and schools and safe, affordable homes. Health equity means increasing opportunities for everyone to live the healthiest life possible, no matter who we are, where we live, or how much money we make.

Both in New Zealand and globally, our ability to address equity challenges in health has improved significantly over the past decades, yet gaps are growing. Persistent disparities in health access, quality of services and outcomes remain. In Aotearoa New Zealand, Māori and Pacific peoples and those in low socioeconomic groups are still the most disadvantaged. The Government has mandated the Ministry of Health to take a bold approach to addressing healthy inequities that delivers tangible changes to health system behaviour, with measurable results over a three- to five-year horizon. The Ministry is developing a cyclical approach that operates around deepening the understanding of equity gaps, shifting thinking about where priorities for investment of time and resources should lie, followed by increasing direct action to address inequality. Al must be part of the solution, building on key strengths and initiatives already successful in Aotearoa such as those using:

- machine learning prediction for scheduling, notably to ease peak usage, resources and surgeries

- digital assistants to educate, answer multi-lingual queries and perform administrative tasks around the clock

- Al digital health professionals, to assess digitised readings and support patient care for less cost

- teachers to fill demand for health experts, dealing with new health challenges in our communities

- machine learning from wearables, to predict health models alongside human longitudinal studies

- auto-diagnosis, pharmacogenomics and personalised treatments with or without genetic testing.

Technology is not a solution; it is part of the solution. Machine learning has incredible predictive power and the ability to learn in supervised or unsupervised systems. Artificial intelligence supports health experts to do more, with new standards of quality. As an investment, Al outcomes rival the investment needed to train teams of doctors and nurses. As an investment in our health, Al has come of age.

There are philosophical and ethical considerations behind a data-led, Al approach. Realities about widening gaps in access to healthcare and issues in health equity are even more complex and cause us to look at ways in which diverse cultural barriers can be ameliorated. If health is our greatest wealth, then addressing health equity must evolve (UNSDG Goal 3, 202I); Al can improve progress in healthcare to address some equity issues.

Artificial Intelligence is transforming health, wellbeing and patient care and some data-driven initiatives in New Zealand can work alongside the behemoth healthcare system to address gaps in health and wellbeing. New Zealand's response to the COVID-19 pandemic is as unique as this country and its people. We can create more equitable healthcare in Aotearoa New Zealand despite some clear and observable gaps as well as appalling statistics. It is in our DNA to do so.

The word 'motu' can mean island, to distance, sever or wound. It can mean a heavy stone or even whooping cough. It can also mean to set free. Addressing healthcare inequity must be a priority.

The capability is here and the will to life health outcomes can overcome barriers to implementation. Health is an investment and it impacts every aspect of life. The opportunity to use data, ML and Al with robotics is vast. With wise partnerships, health equity can be achieved, perhaps even alongside our public health system, because the cost of illness and infirmity is enormous. Al is part of the solution for equitable health and New Zealand can model the pathway to quality healthcare for all New Zealanders and for the world. 
Tavish Sehgal (10) https://orcid.org/0000-0001-6502-786X is an information technology professional and Otago Polytechnic Ltd, Auckland International Campus peer tutor. He specialises in IT cyber security and accessibility and is currently perfecting carbon emission prediction prototypes. Research includes an MS Excel prototype to predict carbon emissions and track individual company emissions plus business applications of IT technologies.

Marianne Cherrington (10) https://orcid.org/0000-0002-1240-2010 is a principal lecturer at Otago Polytechnic Ltd, Auckland International Campus with a focus on Computer Analytics and Sustainability. A lecturer in disruptive innovation, her research into machine learning feature selection algorithms applies in many fields, producing interesting collaborations with local and international partners in many disciplines and sectors. Email: mariannec. op.ac.nz

Correspondence to: Marianne Cherrington, Otago Polytechnic | Te Kura Matatini ki Otago, Forth Street, Private Bag 1910, Dunedin 9054, New Zealand. Email: Marianne.cherrington@op.ac.nz

\section{REFERENCES}

AIA, Sovereign and You (2019). Championing a healthier, better protected NZ. (20 May, 2019). Retrieved from https://www.aia. co.nz/en/campaign/championing-a-healthiermore-protected-nz.html

Airehrour, D., Cherrington, M., \& Rajagopal, K. (2020, November). Odour Detection System for Allergy Sufferers. In 2020 IIth IEEE Annual Information Technology, Electronics and Mobile Communication Conference (IEMCON) (pp. 0193-0200). IEEE.

Ali, M., \& Aittokallio, T. (2019). Machine learning and feature selection for drug response prediction in precision oncology applications. Biophysical Reviews, II(I), 31-39.

Alotaibi, M., \& Yamin, M. (2019, March). Role of robots in healthcare management. In 2019 6th International Conference on Computing for Sustainable Global Development (INDIACom) (pp. I3|I-I3|4). IEEE.

Arcaya, M. C., Arcaya, A. L., \& Subramanian, S. V. (2015). Inequalities in health: definitions, concepts, and theories. Global Health Action, 8(I), 27106

Asif, M., Martiniano, H. F., Vicente, A. M., \& Couto, F. M. (2018). Identifying disease genes using machine learning and gene functional similarities, assessed through Gene Ontology. PloS one, 13(I2), e0208626.

Belsky, D. W., Caspi, A., Arseneault, L., Baccarelli, A., Corcoran, D. L., Gao, X., ... \& Moffitt, T. E. (2020). Quantification of the pace of biological aging in humans through a blood test, the DunedinPoAm DNA methylation algorithm. Elife, 9, e54870.

Bera, K., Schalper, K. A., Rimm, D. L., Velcheti, V., \& Madabhushi, A. (2019). Artificial intelligence in digital pathology-new tools for diagnosis and precision oncology. Nature reviews Clinical oncology, I6(II), 703-7I5.

Bernstein, A., Burnaev, E., Kondratyeva, E., Sushchinskaya, S., Sharaev, M., Andreev, A., ... \& Akzhigitov, R. (2018). Machine Learning pipeline for discovering neuroimaging-based biomarkers in neurology and psychiatry. arXiv preprint arXiv:1804.10163.

Bogue, R. (20 II), "Robots in healthcare", Industrial Robot, 38 (3), 218-223. https://doi.org/I0. II08/0I4399| IIIII22699

Bzdok, D., \& Meyer-Lindenberg, A. (2018). Machine learning for precision psychiatry: opportunities and challenges. Biological Psychiatry: Cognitive Neuroscience and Neuroimaging, 3(3), 223-230.

Campbell, G. (2021, August 3). Terminal but 31-hr wait in ED bed. The New Zealand Herald, p. A7.

Cherrington, M., Airehrour, D., Lu, J., Xu, Q., Wade, S., \& Madanian, S. (2019a, December). Feature Selection Methods for Linked Data: Limitations, Capabilities and Potentials. In Proceedings of the 6th IEEE/ACM International Conference on Big Data Computing, Applications and Technologies (pp. 103-112).

Cherrington, M., Lu, J., Airehrour, D., Thabtah, F., Xu, Q., \& Madanian, S. (2019b, November). Feature Selection: Multi-source and Multi-view Data Limitations, Capabilities and Potentials. In 2019 29th International Telecommunication Networks and Applications Conference (ITNAC) (pp. I-6). IEEE.

Cherrington, M., Thabtah, F., Lu, J., \& Xu, Q. (2019c, April). Feature selection: filter methods performance challenges. In 2019 International Conference on Computer and Information Sciences (ICCIS) (Pp. I-4). IEEE.

Cherrington, M., Lu, Z. J., Xu, Q., Airehrour, D., Madanian, S., \& Dyrkacz, A. (2020). Deep learning decision support for sustainable asset management. In Advances in Asset Management and Condition Monitoring (pp. 537-547). Springer, Cham.

Cherrington, M., Lu, J., Xu, Q., Airehrour, D., \& Wade, S. (202la). Deep learning for sustainable asset management decisionmaking. International Journal of COMADEM, 24(2), 35-4I. 
Cherrington, M., Dunn, I., Airehrour, A., (in press). (202lb). Cracking the Covid-19 Code: Cutting-edge Collaboration. Scope: Contemporary Research Topics (Health and Wellbeing), 2021.

Cherrington, M., Lu, J., Xu, Q., Airehrour, D., \& Wade, S. (202lc). Deep learning for sustainable asset management decisionmaking. International Journal of COMADEM, 24(2), 35-4I.

Coughan, T. (2021, August 2). Urgent order for $3 \mathrm{~m}$ Covid syringes. The New Zealand Herald, p. A5.

Davenport, T. H., \& Glaser, J. (2002, July I). Just-in-Time Delivery Comes to Knowledge Management. Harvard Business Review. https://hbr.org/2002/07/just-in-time-delivery-comes-to-knowledge-management

Davenport, T., \& Kalakota, R. (2019). The potential for artificial intelligence in healthcare. Future Healthcare Journal, 6 (2), 94.

Dilsizian, M. E., \& Siegel, E. L. (2018). Machine meets biology: a primer on artificial intelligence in cardiology and cardiac imaging. Current Cardiology Reports, 20(12), I-7.

eHealth News Features. (2019, February 18). iMOKO tackling issue of inequitable access to healthcare. Health Informatics New Zealand (Albany, Auckland). https://www.hinz.org.nz/news/438034/iMOKO-tackling-issue-of-inequitable-access-tohealthcare.htm

Field A., Butler R. 2018. Virtual Health: Rapid review of evidence and implications. Hamilton: Waikato District Health Board.

Forghani, R., Savadjiev, P., Chatterjee, A., Muthukrishnan, N., Reinhold, C., \& Forghani, B. (2019). Radiomics and artificial intelligence for biomarker and prediction model development in oncology. Computational and structural biotechnology journal, 17, 995. www.ncbi.nlm.nih.gov/pmc/articles/PMC6667772/pdf/main.pdf

Garcia-Canadilla, P., Sanchez-Martinez, S., Crispi, F., \& Bijnens, B. (2020). Machine learning in fetal cardiology: what to expect. Fetal diagnosis and therapy, 47(5), 363-372. https://www.karger.com/Article/Pdf/505021

Health Informatics New Zealand. (May 2020). Genetic testing to drive prescribing. www.hinz.org.nz/news/449084/Genetictesting-to-drive-prescribing

Graue, R. M. (2013). Prediction and optimization techniques to streamline surgical scheduling. (Doctoral dissertation, Massachusetts Institute of Technology). https://dspace.mit.edu/bitstream/handle/I72I.I/82482/862229484-MIT.pdf?sequence=2\&isAllowed=y

Haidegger, T., Kovacs, L., Benyo, B., \& Benyo, Z. (2019). Spatial accuracy of surgical robots. 2009 5th International Symposium on Applied Computational Intelligence and Informatics, 133-138. https://doi.org/I0.1/09/SACI.2009.5136227

Hall, G. L. (2020). Delivering Consistent and Equitable Healthcare. In Patient-Centred Clinical Care for African Americans (pp. 23-35). Springer, Cham.

Hockstein, N. G., Gourin, C. G., Faust, R. A., \& Terris, D. J. (2007). A history of robots: From science fiction to surgical robotics. Journal of Robotic Surgery, I(2), II3-1I8. https://doi.org/I0.1007/s II70I-007-002I-2

Jiang, F., Jiang, Y., Zhi, H., Dong, Y., Li, H., Ma, S., Wang, Y., Dong, Q., Shen, H., \& Wang, Y. (20I7). Artificial intelligence in healthcare: Past, present and future. Stroke and Vascular Neurology, 2(4), 230-243. https://doi.org/l0.1 I36/svn-2017-000 I0 I

Jones, N. (2021, August 2). Health system failing to cope. The New Zealand Herald, p. Al.

Kannan, S., Subbaram, K., Ali, S., \& Kannan, H. (2020). The role of artificial intelligence and machine learning techniques: Race for covid-19 vaccine. Archives of Clinical Infectious Diseases, 15(2). https://sites.kowsarpub.com/archcid/articles//03232.html

Kaplan, A., \& Haenlein, M. (2019). Siri, Siri, in my hand: Who's the fairest in the land? On the interpretations, illustrations, and implications of artificial intelligence. Business Horizons, 62(I), I5-25.

Kapoor, I., Mahajan, C., \& Prabhakar, H. (2019). Robot-Assisted Neurosurgery. In Textbook of Neuroanesthesia and Neurocritical Care (pp. 503-5I0). Springer, Singapore.

Katsaouni, N., Tashkandi, A., Wiese, L., \& Schulz, M. H. (202I). Machine learning based disease prediction from genotype data. Biological Chemistry. https://www.degruyter.com/document/doi/l0.1515/hsz-202I-0109/html

Khan, S. (2012). Vulnerability assessments and their planning implications: a case study of the Hutt Valley, New Zealand. Natural Hazards, 64(2), 1587-1607.

Koelzer, V. H., Sirinukunwattana, K., Rittscher, J., \& Mertz, K. D. (2019). Precision immunoprofiling by image analysis and artificial intelligence. Virchows Archiv, 474(4), 5II-522.

Kvalsvig, A., Barnard, L. T., Gray, L., Wilson, N., \& Baker, M. (2020). Supporting the COVID-19 pandemic response: Surveillance and Outbreak Analytics. Ministry of Health. https://www.health.govt.nz/system/files/documents/ publications/report_for_moh_ covid-19_surveillance_outbreak_analytics_final.pdf

Lalmuanawma, S., Hussain, J., \& Chhakchhuak, L. (2020). Applications of machine learning and artificial intelligence for Covid-19 (SARS-CoV-2) pandemic: A review. Chaos, Solitons \& Fractals, 139, 110059.

Levin, S., Toerper, M., Hamrock, E., Hinson, J. S., Barnes, S., Gardner, H., ... \& Kelen, G. (2018). Machine-learning-based electronic triage more accurately differentiates patients with respect to clinical outcomes compared with the emergency severity index. Annals of emergency medicine, 7I(5), 565-574. https://www.sciencedirect.com/science/article/abs/pii/ S0196064417314427 
Madanian, S., Airehrour, D., Kumar, N., \& Cherrington M., (2018). Smart Cap for Visually Impaired in Disaster Situations. In ISCRAM Asia Pacific 2018 Proceedings-Ist International Conference on Information Systems for Crisis Response and Management Asia Pacific. Wellington.

Madanian, S., Airehrour, D., Cherrington, M., and Joy A., "mHealth and Big-Data Integration: Promises for Healthcare System in India" BMJ Health \& Care Informatics, 2019. https://www.ncbi.nlm.nih.gov/pmc/articles/PMC7062344/pdf/ bmjhci-2019-10007I.pdf

Maddox, T. M., Rumsfeld, J. S., \& Payne, P. R. (2019). Questions for artificial intelligence in health care. JAMA, 32I(I), 31 -32.

Marescaux, J., Leroy, J., Gagner, M., Rubino, F., Mutter, D., Vix, M., Butner, S. E., \& Smith, M. K. (200I). Transatlantic robot-assisted telesurgery. Nature, 4/3(6854), 379-380. https://doi.org/I0.1038/35096636

Meskó, B., Hetényi, G., \& Győrffy, Z. (20I8). Will artificial intelligence solve the human resource crisis in healthcare? BMC health services research, $18(1), 1-4$.

Ministry of Health. (2002). Reducing Inequalities in Health. Wellington, New Zealand: Author. www.health.govt.nz/system/files/ documents/publications/reducineqal.pdf

Moore, C., Patrick, S., Morris, M., Hough, K., Nordstrom, S., Thompson, R., \& Mahoney, L. (2018). Temuka, South Canterbury, New Zealand: Community Assessment, Needs Analysis And Health Promotion. Scope: Contemporary Research Topics (Health and Wellbeing), 2018. https://www.thescopes.org/assets/Uploads/f5d8f2acc0/I73-Scope-Health-and-Wellbeing-3Moore-et-al.pdf

Orion Health. (3 April, 2019). Al Day 2019: Building trustworthy Al for the future. Retrieved from https://orionhealth.com/nz/ knowledge.

Patel, U. K., Anwar, A., Saleem, S., Malik, P., Rasul, B., Patel, K., ... \& Arumaithurai, K. (202I). Artificial intelligence as an emerging technology in the current care of neurological disorders. Journal of Neurology, 268(5), 1623-1642. https://link.springer.com/ article/10.1007/s00415-019-095/8-3

Pedersen, M., Verspoor, K., Jenkinson, M., Law, M., Abbott, D. F., \& Jackson, G. D. (2020). Artificial intelligence for clinical decision support in neurology. Brain Communications, 2(2), fcaa096. https://academic.oup.com/braincomms/article/2/2/ fcaa096/5869431

Peng, L., Peng, M., Liao, B., Huang, G., Li, W., \& Xie, D. (2018). The advances and challenges of deep learning application in biological big data processing. Current Bioinformatics, 13(4), 352-359.

Puaschunder, J. M., Mantl, J., \& Plank, B. (2020). Medicine of the future: The power of Artificial Intelligence (AI) and big data in healthcare. RAIS Journal for Social Sciences, 4(I), I-8. http://journal.rais.education/index.php/raiss/article/download/83/62

Ranev, D., \& Teixeira, J. (2020). History of Computer-Assisted Surgery. The Surgical Clinics of North America, 100(2), $209-218$. https://doi.org/I0.1016/j.suc.2019.1I.00I. https://link.springer.com/chapter/I0.1007/978-3-642-29728-I_I

Runciman, M., Darzi, A., \& Mylonas, G. P. (2019). Soft robotics in minimally invasive surgery. Soft robotics, 6(4), 423-443. https:// www.liebertpub.com/doi/pdfplus/10.1089/soro.2018.0136

Sardar, P., Abbott, J. D., Kundu, A., Aronow, H. D., Granada, J. F., \& Giri, J. (2019). Impact of artificial intelligence on interventional cardiology: from decision-making aid to advanced interventional procedure assistance. Cardiovascular Interventions, 12(14), 1293-1303.

Smith, J. A., Jivraj, J., Wong, R., \& Yang, V. (2016). 30 Years of Neurosurgical Robots: Review and Trends for Manipulators and Associated Navigational Systems. Annals of Biomedical Engineering, 44(4), 836-846. https://doi.org//0.1007/sI0439-015$1475-4$.

Troccaz, J., Dagnino, G., \& Yang, G.-Z. (2019). Frontiers of Medical Robotics: From Concept to Systems to Clinical Translation. Annual Review of Biomedical Engineering, 21, 193-218. https://doi.org/l0.1/46/annurev-bioeng-060418-052502

UNSDG Goal 3 (202I). Department of Economic and Social Affairs. Sustainable Development. https://sdgs.un.org

Vaishya, R., Javaid, M., Khan, I. H., \& Haleem, A. (2020). Artificial Intelligence (AI) applications for COVID-19 pandemic. Diabetes \& Metabolic Syndrome: Clinical Research \& Reviews, 14(4), 337-339.

Vervoort, D., Marvel, F. A., Isakadze, N., Kpodonu, J., \& Martin, S. S. (2020). Digital cardiology: opportunities for disease prevention. Current Cardiovascular Risk Reports, 14(8), I-7.

Xu, J., Yang, P., Xue, S., Sharma, B., Sanchez-Martin, M., Wang, F., ... \& Parikh, B. (2019). Translating cancer genomics into precision medicine with artificial intelligence: applications, challenges and future perspectives. Human Genetics, 138(2), $109-124$.

Yu, K. H., Beam, A. L., \& Kohane, I. S. (20I8). Artificial intelligence in healthcare. Nature Biomedical Engineering, 2(I0), 7I9-73I. https://drive.google.com/file/d/I0U3KnmNY8lgQk3GXnl4sMv7Tp4wsxk-n/view

Zhou, Y., Wang, F., Tang, J., Nussinov, R., \& Cheng, F. (2020). Artificial intelligence in COVID-19 drug repurposing. The Lancet Digital Health. https://www.sciencedirect.com/science/article/pii/S2589750020301928

Zemmar, A., Lozano, A. M., \& Nelson, B. J. (2020). The rise of robots in surgical environments during COVID- 19. Nature Machine Intelligence, 2(I0), 566-572. https://doi.org/I0.1038/s42256-020-00238-2 